\title{
Correction to: Xenopus LAP2 $\beta$ protein knockdown affects location of Lamin B and nucleoporins and has effect on assembly of cell nucleus and cell viability
}

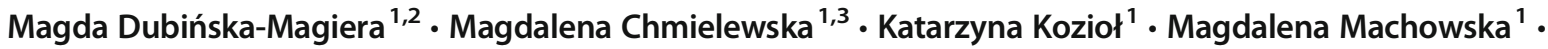 \\ Christopher J. Hutchison ${ }^{4} \cdot$ Martin W. Goldberg $^{4} \cdot$ Ryszard Rzepecki $^{1}$
}

Published online: 7 January 2020

(C) Springer-Verlag GmbH Austria, part of Springer Nature 2020

\section{Correction to: Protoplasma (2016) 253:943-956 \\ https://doi.org/10.1007/s00709-015-0861-y}

The original publication of this paper contains a mistake.

Figure 1 with corrected Panel A and corrected Panel H is shown in this paper. This means that Panel A and Panel $\mathrm{H}$ is prepared from another original images/microscopic captures taken at the same experiments and demonstrating exactly the same staining pattern with the same antibodies, processed in the same way as other images used for preparation of Fig. 1.

The online version of the original article can be found at https://oi.org/ 10.1007/s00709-015-0861-y

Ryszard Rzepecki

rzepecki@ibmb.uni.wroc.pl

1 Laboratory of Nuclear Proteins, Faculty of Biotechnology,

University of Wrocław, Joliot- Curie 14a, 50-383 Wrocław, Poland

2 Department of Animal Developmental Biology, Institute of Experimental Biology, University of Wroclaw, Sienkiewicza 21, 50-335 Wroclaw, Poland

3 Department of Evolutionary Biology and Vertebrate Conservation, University of Wroclaw, Sienkiewicza 21, 50-335 Wroclaw, Poland

4 Integrative Cell Biology Laboratory, School of Biological and Biomedical Sciences, The University of Durham, South Road, Durham DH1 3LE, UK 


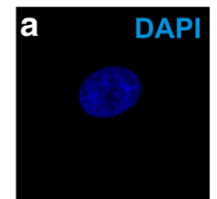

b
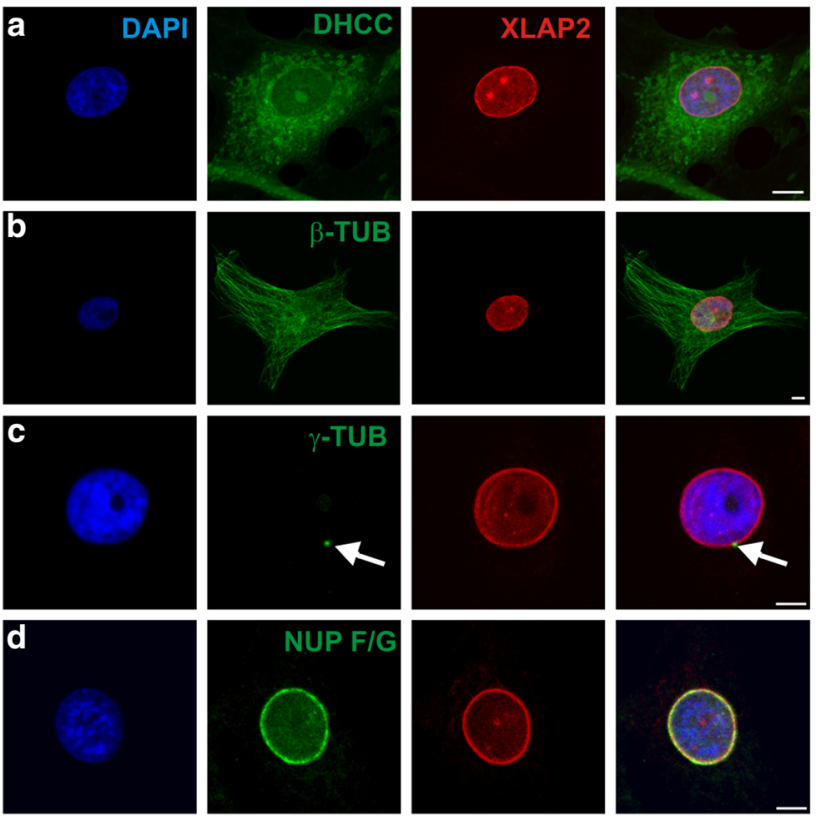

Fig. 1 Panel a was prepared by our mistake from the same original capture/microscopic image as Fig. 4,Panel C from Chmielewska et al 2011 from Cell and Tissue Research (Cell Tissue Res. 2011 Apr;344(1):97-110. doi: https://doi.org/10.1007/s00441-011-1129-2. Epub 2011 Feb 24). They do not look exactly the same because of different magnification/field view. In Chmielewska et al 2011 there is also lamin B2 staining shown which is absent in Fig1A from Protoplasma paper. We would like to put new Fig. 1 Panel a prepared from the same experiment, documenting ecactly the same but prepared from another
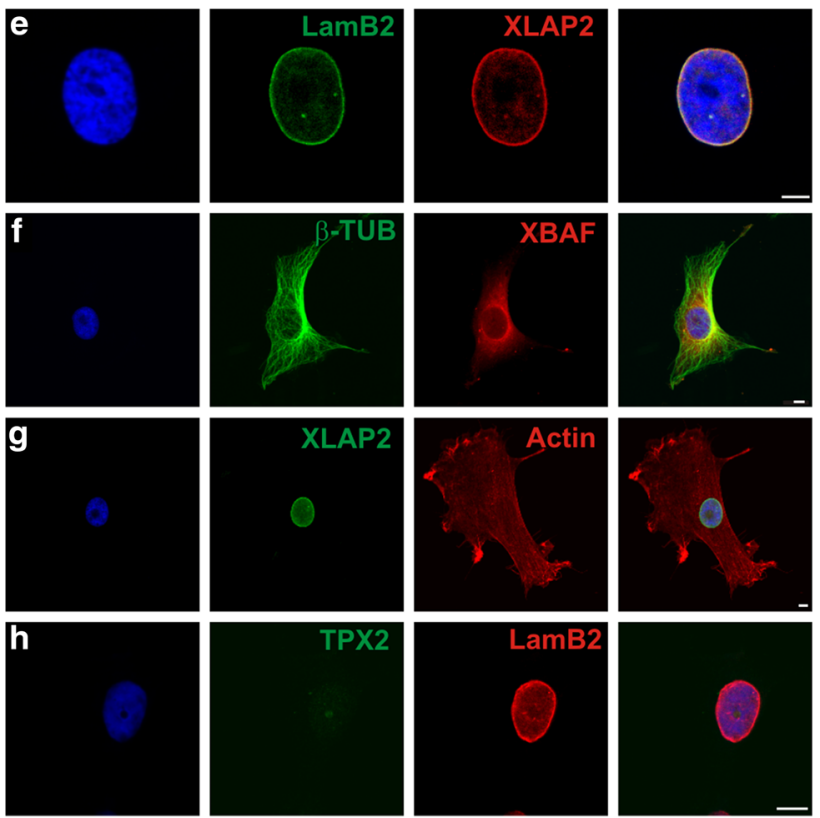

original image we have available from that time. Panel $\mathrm{H}$ was prepared, by our mistake, from the same original capture/microscopic image as Fig. S1 from Protoplasma paper (Dubinska-Magiera et al., 2016) (Protoplasma. 2016 May;253(3):943-56. doi: https://doi.org/10.1007/ s00709-015-0861-y. Epub 2015 Jul 25). They do not look exactly the same because TPX2 and lamin B2 were shown in different colors. Also the zoom is different. We would like to put new Fig. 1 Panel h prepared from the same experiment, documenting exactly the same but prepared from another original image we have available from that time 